\title{
Culture Integration in Translating
}

\author{
Xiao Geng \\ Qingdao University of Science and Technology, Qingdao, China \\ Email: gxdonna@126.com
}

\begin{abstract}
Nowadays, with the development of the society, culture communication becomes more and more frequent. Different languages come into contact with each other. Since every language is a part of culture, it can not but serve and reflect culture needs. But culture also exerts a strong influence on language, especially in translation. When we translate, we should not only focus on the distinction between the foreign language and our mother tongue. We should also pay attention to the numerous features shared by the two languages. Not only differences exist in different languages, but also a great deal in common between them. Translation is affected by customs habits, history, etc. Culture plays an important part in translation. Culture should be integrated in translating.
\end{abstract}

Index Terms - culture, integration, translating

\section{INTRODUCTION}

It is a flat fact that cultural factors play a crucial role in the efficiency of human communication and that the importance of culture integration with foreign language translation has been realized by more and more people, especially by linguists and experts in the foreign language teaching world at home and abroad. And there have been, both in theory and practice, quite a number of findings or insights on this subject since 1990s, which is encouraging and significant. However, to our regret, there are some different views on this subject and there do exist such people who take English as a culturally neutral instrument or a purely linguistic code. A new model for the successful integration of culture into the foreign language teaching practice has not yet been constructed.

From my teaching experience and study on this subject I had come to realized that language and culture are inseparable and that the relationship between language and culture is dynamic rather than static. We Chinese must be aware that "the variety generally used for international communication is characterized by minimal use of metaphorical and idiomatic expressions, and neutralization of regional difference"(Saville-Traike,1982:105)At the same time, we should not pursue the possibility of finding a culture-free variety of English which can be used by English Speakers or non-English speakers for international communication. In other words, "A language might remain culture-free if its users were also outside any culture; but since it seems unlikely that such persons exist, we can say that in practice a language could be culture-free only if it remained unused, since once it was explain for communication between people it would inevitable be used in accordance with one or another set of culture norms." English has never been culture-free, no matter whether it is used by scientists, by people in different English speaking countries or by people in NonEnglish speaking countries. English is indeed a rich source, providing information about cultures in many countries. Besides, learning and using English seems to be a process in which native culture and the culture to which English originally relates are brought tighter to interact. This interaction takes place both internally and externally.

Academic translating competence comprises attitudes, knowledge, skills, and strategies that enable one to produce right translation in accordance with the expectations of the academic discourse community. The translation of words and phrases is more difficult to master than article translation. Sometimes even a word and a phrase takes much time to establish in translation. Translation of words and phrase should obey thee translation criteria "faithfulness, expressiveness and elegance."(Luxun). These standards are useful to the translation.

But sometimes we cannot translate words and phrases only according to the above stands. There is one more important thing we should not neglect: culture influence upon the translation of words and phrases. There are several ways of translation, such as pure translation, pure semantic translation etc. Culture factor is an important part we should consider. So in the translating, culture should be integrated in translating.

\section{CUlture InfluENCE UPON TRANSLATION IN PRACTICE}

\section{A. The Same Words Have Different Meaning and the Different Words Have Same Meanings in Different Cultures.}

Since culture is a particular system of part, though, and customs of a society, the heated argument has been further extended to the relationship between language and culture. Indifferent cultures, the same word may have different meaning and different words may have the same meaning. So, in the course of translation, whether a translator's understanding to a word or a phrase is right or not largely depends on his understanding to the future.

Examples as follows:

The word ancient has different meaning in different cultures Both Chinese and Europe have the word. But in China 
we mean Qin and Han dynasties while in Europe they usually mean ancient Greece and Roman times. China and Europe have different history. "Ancient" means different periods in history. So that the reader can have the exact understanding.

\section{B. Unequivalence of English Original Works and Chinese Translation}

"Faithfulness" is the most important criterion for translation. Faithfulness also includes the keeping of the original work. But because of different cultures, English original works and Chinese translation cannot always be equivalent. In this case, we should avoid word-for-word translation.

We can translate the English metaphor "She is a fox" word by word, but we cannot translate "She is a cat" from the literal meaning. In many different cultures, including English and Chinese cultures, we often connect "fox" with "sly". This is the common trait in many different cultures. But it is not the outcome of Chinese culture to connect "cat" with "a woman with evil intent". Because the semantic meanings are not corresponding, the original work and translation cannot be entirely equivalent.

How to translate "pig" and "fig"? if we translate them respectively into "zhu" and "wuhuaguo", we will make the readers perplexed. "Zhu" has no connection with "wuhuaguo". So when we translate "fig", we can use a Chinese character "shu" which has the same rhyming word with "zhu". This keeps the flavor of the original work and there is no need to explain.

\section{English and Chinese - the Individual and Distinct System of Two Entirely Different Languages}

English and Chinese are two entirely different languages. Each has an individual and distinct system. There are lots of dissimilarities between them. Because of this, we have to be familiar with both the language and the different cultures.

(1) different meanings of "peasant" and "farmer"

Nowadays, we often translate "nongmin" into "peasant". In fact, "peasant" in modern English has a strong derogatory sense. In dictionary, the meaning of "peasant" is: a) one of a chiefly European class that tills the soil as small free landowners or hired labors b) a rascally person c) a rather uneducated, uncouth person in the low income group. Now people in the English speaking countries call people who work for agriculture farmers or farm workers. Farmer is a person who cultivates lands or crops or raises live stocks. Farmer is a proper name for our Chinese "nongmin", though "peasant" has been used for a long time by a number of Chinese people. A translator should not only translate the works but also impact the thought of people through translation and change their wrong ideas formed years ago.

(2) over-literal translation in "breakfast" and "white hands"

There are many words and phrases which we cannot translate over-literally. We must consider the culture factor. For example, there are two ways of translating the English word "breakfast". One is "the first meal of the day" which is an interpretation of the word in terms of its actual referent. And the over-literal way of translating it will result in "the meal which breaks a period of fasting". Though this looks much more faithful to the original meaning, it is surely misleading. The phrase "white hands" is "baishou" in Chinese if we use word-for-word translation. It means "start from scratch" or "build up from nothing". But in English "which hands" means "pure", "unsullied". When we say "He has white hands", we cannot understand this sentence as "His hand is white ". In English it means "He is unstained".

(3) the translation of "restroom"

Take "restroom" for another example, we translate the word "rest" into "xiuxi" and "room" into "shi". So many people take it for granted that "rest-room" is "xiuxishi". But in English "rest-room" is a lavatory in a public building. Suppose a foreign teacher went into a Teacher's rest-room to get relieved. How disappointed and embarrassed he will be when he finds there is no toilet.

(4) misunderstanding of "wine" and "spirits"

Out Chinese people like to translate "baijiu" into "white wine". In China "baijiu" is distilled out of water. The ethyl alcohol degree is usually above 50. but in English white wine is brewed out of grapes. The ethyl alcohol degree is only about 15. "spirits" or "liquor" should be used to the liquid distilled and "wine" is general name for the liquid brewed out of grapes.

(5) disparity between cultures

There are more other translation of words and phrases influenced by culture. We use "huangseluxiang" while the American use "blue video". We use "hongyanbing" while they use "green-eyed monster". No translation can exist without culture. No translation can be separated from culture. Even though we say "shaitaiyan" in Chinese, no one of us will admit that we think that it is people who bathe the sun rather than the sun bathing people. The translation is affected by the way of thinking in the culture of different languages. There seems to exist some disparities between what people actually think and what is conveyed in the over-literal translation.

(6) necessary explanation in translation of "dragon"

Different cultures make it necessary for the translator to make some explanation after translation. For example, there are two ways of translating "wangzichenglong" 8 . One is "long to see one's son succeed in life. Another is "long to see one's son become a dragon (i.e. win success in the world)". The first is liberal translation and the second is literal translation with explanation. The explanation is necessary because dragon has different meanings in English and Chinese. In the Bible, dragon is the symbol of evil. It is formidable for Englishman and American. But for our Chinese 
dragon is the symbol of emperor.

\section{GLOBALIZATION AND RECOGNITION OF SOME TRANSLATION}

\section{A. Loanwords and Globalization}

In the recent ten years, the contact between China and other countries become more and more frequent. More and more translation works appear in many fields, such as in economy, politics, trade and tourism. Culture communication is becoming more and more frequent. Different culture phenomenon is familiar to different people. There are some words and phrases being accepted by other cultures and popular in other cultures. Cases in point are qigong, kungfu, etc. There words have been accepted by English speaking countries. Some words like "CD", "VCD", "OK" and "E-mail" are used directly instead of being translated into Chinese.

\section{B. Recognition of Some Translation like "Telephone"}

In 1930s and 1950s, "telephone", "laser" appeared. But at that time, people did not know what they were. As years passed, people know more about these things and change their names that were not right many years ago. The translator is intelligent to combine the euphony with the mellowness of the wine and hospitality of welcoming the guest. All these examples show the culture influence upon the translation of words and phrases.

\section{CONCLUSION}

Leaning a language is a kind of learning the culture and habit of the country where the language is spoken. Translation, we should learn the different cultures, including its tradition, habits, social customs, morals and so on. Culture exerts strong influence on language. In the translation of words and phrases, culture background is essential. A translator without understanding the culture cannot translate well. We should take the culture factor as an important part in translation and translate words and phrases according to the rules of translation so as to get rid of unreasonable translation.

\section{REFERENCES}

[1] Guo Zhzhang, li Qingsheng. (1996). English and Chinese Translation. Wuhan: The Press of Wuhan University.

[2] Hu Zhuanglin, Liu Runqing, Li Yanfu. (1988). The Language Teaching. Beijing: The Press of Beijing University

[3] Lin Huangtian. (1988). Chinese Translation. Beijing: The Post Office of Beijing.

[4] Silva, Tony, and Colleen Brice. (2004). Research: The Student's Guide to Writing Research Papers. New York: Pearson Education, 4th edn.

[5] Vygotsky, Lev S. (1978). Mind in Society: the Development of Higher Psychological Processes. Cambridge, MA: MIT Press.

[6] Warschauer, Mark. (1997). 'Computer Mediated Collaborative Leaning: Theory and Practice'. The Modern Language Journal 81: 470-81.

[7] Weissberg, Robert, and Suzanne Bucker. (1990). Writing Up Research: Experimental Research Report Writing for Students of English (Englewood Cliffs, NJ: Prentice-Hall).

Xiao Geng was born in Weihai, China in 1970. She received her M.A. degree in linguistics from Qufu Normal University, China in 2004.

She is currently an associate professor in the School of Foreign Languages, Qingdao University of science and Technology, Qingdao, China. Her research interests include teaching methods and the Second Language Acquisition.

Prof. Geng is a member of the Institute of Linguistic Study. 